\title{
Prevalence of latent iron deficiency in early pregnancy in a tertiary care hospital in Sri Lanka: A cross-sectional study
}

\author{
Neelakshi De Silva ${ }^{1}$, Senani Williams ${ }^{2}$, Durgadevi Moratuwagama ${ }^{3}$, Indika Siriwardena ${ }^{4}$, \\ Anandadeep Mandal ${ }^{5}$, Carmeline Motha ${ }^{2}$, Thilina Palihawadena ${ }^{2}$, and A Pathmeswaren ${ }^{2}$ \\ ${ }^{1}$ Walsall Manor Hospital \\ ${ }^{2}$ University of Kelaniya \\ ${ }^{3}$ Betsi Cadwaladr University Health Board \\ ${ }^{4}$ Ministry of Justice of Sri Lanka \\ ${ }^{5}$ University of Birmingham
}

November 5, 2020

\begin{abstract}
Objectives To estimate the prevalence of latent iron deficiency (LID) among pregnant women, assess LID in relation to parity, age, education, and household income, and to determine correlations between LID and red cell indices, red cell distribution width (RDW), and red cell morphology. Design Cross-sectional design Setting North Colombo Teaching Hospital, Sri Lanka. Sample Participants comprised 355 pregnant women with normal haemoglobin levels seeking antenatal care within $<20$ weeks of gestation. Method Data were obtained from interviews and antenatal records. Participant full blood count (FBC), serum ferritin levels, and blood films were analysed. Main Outcome Measures Prevalence of LID, demographic data (age, parity, period of gestation, gap between pregnancies, income, and education), and blood film morphology. Results LID prevalence was $54 \%$. Statistical significance for the gap between pregnancies being $<2$ years was observed but not for participant's age, parity, income, and education. Blood film morphology depicted statistically significant presence of hypochromic microcytic red cells and pencil cells. RDW was significant in indicating the presence of LID. Among those with LID, 25\% had ferritin level in the iron deficiency range. Conclusions LID is highly prevalent in early pregnancy and $25 \%$ of participants had ferritin levels in the iron deficiency range. Presence of raised RDW, hypochromic microcytic red cells, pencil cells, and $<2$ years' gap between pregnancies were indicators of LID. To identify pregnant women with LID, blood film, haemoglobin, and RDW could be recommended as basic tests, and ferritin test as an affirmative one.
\end{abstract}

Prevalence of latent iron deficiency in early pregnancy in a tertiary care hospital in Sri Lanka: A cross sectional study

Hyacinth N. De Silva ${ }^{*}$, Senani Williams ${ }^{2}$, Durgadevi Moratuwagama ${ }^{3}$, Indika Siriwardena ${ }^{4}$, Anandadeep Mandal $^{5}$, Carmeline Motha ${ }^{6}$, Thilina Palihawadena ${ }^{6}$, A Pathmeswaren $^{7}$

${ }^{1}$ Haematology, Walsall Manor Hospital, Birmingham, United Kingdom

${ }^{2}$ Haematology, University of Kelaniya, Ragama, Sri Lanka

${ }^{3}$ Haematology, Betsi Cadwaladr University Health Board, United Kingdom

${ }^{4}$ Policy and Programmes, Ministry of Justice, Human Rights and Legal Reforms, Colombo, Sri Lanka

${ }^{5}$ Mathematical Finance, University of Birmingham, Birmingham, United Kingdom,

${ }^{6}$ Department of Obstetrics \& Gynaecology, University of Kelaniya, Ragama, Sri Lanka 
${ }^{7}$ Department of Public Health, University of Kelaniya, Ragama, Sri Lanka

*Corresponding author

Neelakshi De Silva

45, Old farm drive, Marston Green, Birmingham. B37 7WH

07799947040, 07510688449

neelakshi.desilva1@nhs.net

Abstract

Objectives

To estimate the prevalence of latent iron deficiency (LID) among pregnant women, assess LID in relation to parity, age, education, and household income, and to determine correlations between LID and red cell indices, red cell distribution width (RDW), and red cell morphology.

\section{Design}

Cross sectional design

\section{Setting}

North Colombo Teaching Hospital, Sri Lanka.

\section{Sample}

Participants comprised 355 pregnant women with normal haemoglobin levels seeking antenatal care within $<20$ weeks of gestation.

\section{Method}

Data were obtained from interviews and antenatal records. Participant full blood count (FBC), serum ferritin levels, and blood films were analysed.

\section{Main Outcome Measures}

Prevalence of LID, demographic data (age, parity, period of gestation, gap between pregnancies, income, and education), and blood film morphology.

\section{Results}

LID prevalence was 54\%. Statistical significance for the gap between pregnancies being $<2$ years was observed but not for participant's age, parity, income, and education. Blood film morphology depicted statistically significant presence of hypochromic microcytic red cells and pencil cells. RDW was significant in indicating the presence of LID. Among those with LID, 25\% had ferritin level in iron deficiency range.

\section{Conclusions}

LID is highly prevalent in early pregnancy and $25 \%$ of participants had ferritin levels in the iron deficiency range. Presence of raised RDW, hypochromic microcytic red cells, pencil cells, and $<2$ years' gap between pregnancies were indicators of LID. To identify pregnant women with LID, blood film, haemoglobin, and RDW could be recommended as basic tests, and ferritin test as an affirmative one.

Keywords : Latent iron deficiency, iron deficiency anaemia, pregnancy, red cell distribution width, full blood count, serum ferritin

\section{Tweetable Abstract:}

Latent iron deficiency is prevalent in pregnant women and can be identified through blood film, haemoglobin, serum ferritin, and red cell distribution width tests 


\section{Introduction}

Worldwide, iron deficiency is the most common nutritional deficiency ${ }^{(1,2)}$. Approximately $20 \%$ of pregnant women worldwide suffer from anaemia due to this ${ }^{(3)}$.

During pregnancy, iron deficiency risk increases due to the requirement of additional iron to sustain the expansion of red cell mass, and the growth of the fetus and placenta ${ }^{(1)}$. Iron deficiency contributes to adverse pregnancy outcomes such as intrauterine growth retardation and perinatal death ${ }^{(4,2)}$. Some studies have shown maternal iron deficiency at delivery to be associated with lower serum ferritin levels in the cord blood of neonates, especially when the mother's serum ferritin level was below $13 \mu \mathrm{g} / \mathrm{l}^{(5,6,7)}$. This perhaps explains why iron deficiency impacts fetal and infant well-being by affecting brain development, auditory neural maturation, and increasing the risk of poorer cognitive, motor, social-emotional, and neurophysiologic development ${ }^{(4,8,9)}$.

Iron deficiency is progressive: iron stores in the body gradually diminish, resulting in iron deficiency anaemia $(\text { IDA })^{(5,10)}$. Latent iron deficiency (LID) occurs when iron stores are exhausted but the blood haemoglobin $(\mathrm{Hb})$ levels are within normal limits ${ }^{(11)}$. Hence women with LID are at a higher risk of developing IDA associated with pregnancy complications, if not for early detection and treatment.

Assessment of $\mathrm{Hb}$ level alone, however, is not adequate to identify LID ${ }^{(12)}$. Estimation of serum ferritin is the more pertinent method to detect body iron stores ${ }^{(5,13)}$, ${ }^{(5)}$. A serum ferritin level of $<30 \mathrm{ug} / \mathrm{l}$ in pregnancy is considered as $\operatorname{LID}^{(5)}$. Even though serum ferritin is currently available in most general hospitals in Sri Lanka, it is an expensive test and is not performed routinely. Therefore, surrogate screening tests are needed to identify women with LID.

In LID, the mean corpuscular volume (MCV) usually remains within normal limits, but a few microcytes may be detected on a blood smear ${ }^{(14)}$. Therefore, increased red cell distribution width (RDW) may be an early indicator for $\operatorname{LID}^{(15,16)}$. Red cell indices and RDW are low-cost investigations included in the full blood count (FBC), which can be undertaken in hospitals in Sri Lanka and other developing countries.

The prevalence of LID among pregnant women in Sri Lanka is currently not well known. Better awareness would enable clinicians to act within the routine antenatal care plan. Thus, the primary objective of this study was to assess the prevalence of LID in early pregnancy. Furthermore, the secondary objective was to identify LID using red cell indices, RDW, and blood films as surrogate screening tools.

\section{Methods}

This cross sectional study was conducted in the obstetrics and gynaecology units of North Colombo Teaching Hospital, Sri Lanka from December 2014 to January 2017. All pregnant women with normal Hb levels ([?]110 $\mathrm{g} / \mathrm{l}$ in $<12$ weeks, $>105 \mathrm{~g} / \mathrm{l}$ in 13-20 weeks of gestation), booked for antenatal care within $<20$ weeks of gestation, were the potential study subjects ${ }^{(5)}$. Among them, those with haematological diseases, active infections, liver disease, chronic connective tissue disorders, malignancies, and haemoglobinopathies were excluded $^{(4)}$. Written informed consent was obtained from the selected subjects. Data were gathered from interviews and antenatal records. The study was approved by the Ethics Review Committee, Faculty of Medicine, University of Kelaniya, Sri Lanka.

Blood samples were collected for FBC, blood film, and serum ferritin level. Any further treatment or followup was in accordance with routine clinical practice. Full blood count was analysed by a five-part Beckman Coulter analyser, while serum ferritin was estimated by a two-step immune metric technique. Blood film morphology was reported by three independent observers. If a blood film showed features of the exclusion criteria listed above, the subject's data were excluded. Existing data from a similar Sri Lankan population at the booking visit estimated the LID to be $18 \%^{(10,17)}$.

The sample size of the cross-sectional study was 355, calculated on the basis of $4 \%$ acceptable difference at a $95 \%$ confidence interval. The preliminary statistical analysis was limited to descriptive statistics. IBM SPSS (version 16) was used for socio-demographic, FBC, and morphology data analysis. Pearson's chi squared test 
was applied to determine statistical significance. The independent t-test analysed the effect of prophylactic use of haematinics. Receiver Operating Characteristic (ROC) curves were constructed to identify optimal cut off values for red cell indices $(4,12)$. Statistically significant $\mathrm{P}$ value was taken as $<0.05$.

\section{Results}

The total number of pregnant women under 20 weeks of gestation was 355 . While 192 women were in the LID group (54\%),163 women were a part of the normal group (46\%).

Majority (56\%) were between 21-30 years. Primi gravida pregnancies were noted among $43.2 \%$ in LID group, while it varied in the normal group. Majority were with a period of gestation of 13 to 20 weeks (56.2\% in the LID group, $46.6 \%$ in the normal group). Gap of less than 2 years between pregnancies was $60.4 \%$ in LID and $44.2 \%$ in normal group. Most of the subjects (72\%) were well educated to GCE Ordinary level or above, yet $89.6 \%$ of them were unemployed. Approximately, $68 \%$ of spouses were skilled workers. Nearly half of the sample belonged to low-income families with monthly earnings $<$ LKR 50,000 (USD 278). Of the demographic data, statistical significance $(\mathrm{P}=0.006)$ was noted only for the gap between pregnancies being $<2$ years, but not for participants' age, parity, period of gestation, income, or education.

The values for $\mathrm{Hb}, \mathrm{RBC}$, Red cell indices, and RDW, according to the iron status, are shown in Table 1, along with descriptive statistics. Considering the FBC parameters, the RDW values for participants in the LID vs. normal group were significant $(\mathrm{P}=0.001)$. No significant differences for $\mathrm{Hb}, \mathrm{RBC}, \mathrm{MCV}$, mean corpuscular hemoglobin $(\mathrm{MCH})$, and mean corpuscular haemoglobin concentration (MCHC) values were found between the groups.

Blood film morphology depicted a statistically significant presence of hypochromic microcytic red cells $(\mathrm{P}=0.001)$ and pencil cells $(\mathrm{P}=0.007)$ between groups. Morphology findings according to iron status are shown in Table 2 .

Among the LID group, $25 \%$ participants had ferritin levels in the iron deficiency range $(<15 \mu \mathrm{g} / \mathrm{l})$. Although $43 \%$ of participants in the cohort were on iron supplements, there was no statistical difference for haematinics between the two groups. The ROC was constructed for red cell indices to identify predictive values. Significant area under the curve (AUC) and $\mathrm{P}$ values $(\mathrm{P}=0.0001)$ were noted only for RDW.

\section{Discussion}

\section{Main findings}

In the study group, $54 \%$ of the participants had LID, that is, they had depleted iron stores from the start of pregnancy. Therefore, they would be at high risk for IDA. Notably, one fourth of the participants in the LID group had serum ferritin at a severe iron deficiency level $(<15 \mathrm{ug} / \mathrm{L})$. They had normal Hb levels, hence their deficiency would not have been identified by routine tests done in the antenatal clinics. They, thus, would not have received appropriate care to prevent anaemia with the progression of pregnancy. Their new-born would also have been at the risk of developing cognitive impairment associated with IDA.

\section{Strengths and limitations}

Though socio-demographic factors could influence iron deficiency status, the reduced gap between pregnancies was the only significant risk factor identified. The finding of this study was compatible with other studies such as the one by Lazović and Pocekovac ${ }^{(18)}$.

Haemoglobin on its own is a poor indicator of iron deficiency, and previous studies have emphasised its poor sensitivity for identifying iron deficiency ${ }^{(19,20)}$. Since the number of women with LID was high, reflecting an overall high incidence in the population, it is important to have easily assessable and affordable tests to screen for iron deficiency. Due to the high cost and low availability of the serum ferritin estimation method, the red cell indices, RDW, and blood film were considered as substitute screening tests. However, the correlation of red cell indices with LID did not show any statistical significance. This may be due to the 
counter effects of pregnancy induced changes, especially the MCV, as it increases by $4 \mathrm{fl}$ with progression of $\operatorname{pregnancy}^{(21)}$. A study by Tiwari et al. among 100 pregnant women in India supported these findings ${ }^{(21)}$.

It is known that few microcytes can be seen in the blood film in $\operatorname{LID}^{(22)}$. This could contribute to the increase in $\mathrm{RDW}^{(16,23)}$. Though the study by Tiwari et al. ${ }^{(21)}$ had shown no significant indicators to detect LID, our data showed a significant increase of RDW in the LID group. Blood film morphology observed by three haematologists revealed that hypochromic microcytic red cells and pencil cells were present in a significant number of participants with LID. These two tests (blood film and RDW) can be used independently or in combination as routine tests to screen for LID. The use of ROC cut off values for red cell indices to detect LID has been shown by Rabindrakumar et al. ${ }^{(4)}$, with a smaller number (70) of participants. However, such results were not reflected in the analysis of the present study, even with a larger sample size of 194 .

Due to logistical constraints, the study has one limitation: subjects could not be followed-up with to monitor their pregnancy outcome.

\section{Conclusion}

Study results revealed a high prevalence of LID in early pregnancy with one fourth of the sample having ferritin levels in the iron deficiency region. The presence of raised RDW, hypochromic microcytic red cells, and pencil cells acted as indicators of LID. It is recommended that to identify pregnant women with LID, blood film, Hb level, and RDW could be measured as basic screening tests. Serum ferritin test could be recommended as an affirmative follow-up. The step-wise testing suggested in this study is a cost-effective procedure, especially suitable for resource-strapped obstetrics and gynaecology clinics in developing countries.

\section{Acknowledgements}

1. M.D. Dabarera

2. S.K. Rodrigo

3. P. Ranasinghe

4. G.A.C. De Silva

\section{Disclosure of interests}

There are no competing interests to be disclosed.

\section{Contribution to authorship}

HND is the main and corresponding author. She contributed to the study by writing the proposal and collecting the clinical data from the pregnant women. She was the first observer for the blood film. The abstract and final research paper was written by her under the guidance of co-authors.

SW was the main supervisor for the study. She provided guidance on conducting the haematology procedures and acted as an independent observer for the blood films. Furthermore, she contributed to the writing of the abstract and the main research paper.

DM contributed to the research by being the second independent observer for blood films. She provided guidance on forming information leaflets on the research. Furthermore, she contributed to the writing of the abstract and the main research paper.

IS was the primary statistician for the study.

$\mathrm{AM}$ and $\mathrm{AP}$ were contributors to different parts of the statistical analyses, and they rechecked statistic results for coherence.

TP was the main author who provided the guidance for the concept of the research. He was involved in writing up the research proposal for the ethical clearance. 
CM provided guidance on obstetrics concept of the research. She was initially involved in developing the concept and for writing up the research proposal for the ethical clearance.

\section{Details of ethics approval}

The study was approved by the Ethical Review Committee of the Faculty of Medicine, University of Kelaniya, Ragama, in November 2014.

(ref. P/228/11/2014).

\section{Funding}

The funding for the study was provided by the North Colombo Teaching Hospital, Sri Lanka. It served as the research setting for the present study. It did not include any external peer reviews or priority assessments.

\section{References}

1. Tang G, Lausman A, Abdulrehman J, Petrucci J, Nisenbaum R, Hicks LK, et al. Prevalence of iron deficiency and iron deficiency anemia during pregnancy: a single centre Canadian study. Blood. 2019;1343389. doi:https://doi.org/10.1182/asheducation-2017.1.152

2. Breymann C, Auerbach M. Iron deficiency in gynecology and obstetrics: clinical implications and management. Am. J. Hematol. 2017;152-159. doi:10.1182/asheducation-2017.1.152

3. World Health Organization [Internet]. Daily iron and folic acid supplementation during pregnancy; 2020 [cited 2019/02/11]. Available from: who.int/elena/titles/daily_iron_pregnancy/en/

4. Rabindrakumar MSK, Wickramasinghe VP, Gooneratne L, Arambepola C, Senanayake H, Thoradeniya T. The role of haematological indices in predicting early iron deficiency among pregnant women in an urban area of Sri Lanka. BMC Hematol. 2018;18-37. doi:10.1186/s12878-018-0131-2

5. Pavord S, Daru J, Prasannan N, Robinson S, Stanworth S, Girling J. UK guidelines on the management of iron deficiency in pregnancy. BJ Haem. 2020;188:819-830. doi:10.1111/bjh.16221

6. Hokama T, Takenaka S, Hirayama K, Yara A, Yoshida K, Itokazu K, et al. Iron Status of newborns born to iron deficient anaemic mothers. JTropPediatrics. 1996;42:75-77.

7. Shao J, Lou J, Rao R, Georgieff MK, Kaciroti N, Felt BT, et al. Maternal serum ferritin concentration is positively associated with newborn iron stores in women with low ferritin status in late pregnancy. J Nutr. 2012;142:2004-9. doi:10.3945/jn.112.162362

8. Choudhury V, Amin SB, Agarwal A, Srivastava LM, Soni A, Saluja S. Latent iron deficiency at birth influences auditory neural maturation in late preterm and term infants. Am J ClinNutr. 2015;102:1030-4. doi:10.3945/ajcn.115.113084

9. Juula SE, Dermanb RJ, Auerbachca M. Perinatal iron deficiency: implications for mothers and infants. Neonatology. 2019;115:269-274. doi:10.1159/000495978

10. Palihawadana TS, Goonewardene IMR, Motha MBC, Williams HAS. Iron deficiency anaemia in pregnancy: Diagnosis, prevention and treatment. Sri Lanka J. Obstet. Gynaecol. 2014;61-65. doi:10.4038/sljog.v36i3.7713

11. Greer JP, Arber DA, Glader B, et al., editors. Wintrobe's Clinical Hematology. $13^{\text {th }}$ ed. Philadelphia: Wolters Kluwer Lippincott Williams \& Wilkins Health; 2014.

12. Senadheera D, Goonewardene M, Mampitiya I. Anaemia and iron deficiency in pregnant women attending an antenatal clinic in a teaching hospital in southern Sri Lanka. Ceylon Med J. 2017;62:175-183. doi:10.4038/cmj.v62i3.8521.

13. World Health Organization [Internet]. WHO Guideline on use of ferritin concentrations to assess iron status in individuals and populations; 2020. Available from: apps.who.int/iris/handle/10665/331505 
14. Alexander HD, Sherlock JP, Bharucha C. Red cell indices as predictors of iron depletion in blood donors. Int J Lab Haem. 2000;22:253-258. doi:10.1046/j.1365-2257.2000.00323.x

15. Choudhary M, Sharma D, Shekhawat DS, Dab D. Significance of red cell distribution width in the diagnosis of iron deficiency anemia: an observational study from India. J Pediatr Neonatal Care. 2015;3:00102. doi:10.15406/jpnc.2015.02.00102

16. Sultana GS, Haque SA, Sultana T, Rahman Q, Ahmed AN. Role of red cell distribution width (RDW) in the detection of iron deficiency anaemia in pregnancy within the first 20 weeks of gestation. Bangladesh Med Res Counc Bull. 2011;37:102-105. doi: 10.3329/bmrcb.v37i3.9122

17. Chathurani U, Dharshika I, Galgamuwa D, Wickramasinghe ND, Agampodi TC, Agampodi SB. Anaemia in pregnancy in the district of Anuradhapura, Sri Lanka- need for updating prevalence data and screening strategies. Ceylon Med J. 2012;57:101-106. doi: 10.4038/cmj.v57i3.4148

18. Lazović N, Pocekovac P. The importance of time intervals between childbirth and anemia in pregnancy. SrpArhCelokLek. 1996;124:307-10.

19. Jaime-Pérez JC, García-Arellano G, Méndez-Ramírez N, González-Llano Ó, Gómez-Almaguer D. Evaluation of hemoglobin performance in the assessment of iron stores in feto-maternal pairs in a high-risk population: Receiver operating characteristic curve analysis. Rev Bras HematolHemoter. 2015;37:178-83. doi:10.1016/j.bjhh.2015.02.002

20. Salvi CC, Braga MC, Batista FM. Diagnostic accuracy of hemoglobin for iron deficiency in pregnancy: disclosing results of a cited clinical trial. Rev PanamSaludPublica. 2014;36:110-6.

21. Tiwari M, Kotwal J, Kotwal A, Mishra P, Dutta V, Chopra S. Correlation of haemoglobin and red cell indices with serum ferritin in Indian women in second and third trimester of pregnancy. MedJ Armed Forces India. 2013;69:31-36. doi:10.1016/j.mjafi.2012.07.016

22. Urrechaga E, Borque L, Escanero JF. Clinical value of hypochromia markers in the detection of latent iron deficiency in non anemic premenopausal women. J Clin Lab Anal. 2016;30(5):623-627. doi:10.1002/jcla.21912

23. Uchida T. Change in red blood cell distribution width with iron deficiency. IntJLabHematol. 1989;11:117121. doi:10.1111/j.1365-2257.1989.tb00193.x

Tables/Figures caption list

Table 01: Data from FBC test from LID and normal group

Table 02: Morphology data from blood film analysis

Table 1 Data from Full Blood Count (FBC) test from Latent Iron Deficiency (LID) and Normal group

\begin{tabular}{lllllllll}
\hline & LID & LID & LID & LID & Normal & Normal & Normal & Normal \\
\hline & Mean & Median & Mode & Standard Deviation & Mean & Median & Mode & Standard Deviation \\
$\mathrm{Hb}$ & 11.9 & 11.7 & 11.2 & 0.9 & 12.3 & 12.2 & 11.9 & 0.9 \\
$\mathrm{RBC}$ & 4.36 & 4.34 & 4.13 & 0.44 & 4.43 & 4.43 & 4.43 & 0.42 \\
$\mathrm{MCV}$ & 86 & 86 & 83 & 5 & 87 & 88 & 85 & 4 \\
MCH & 27.4 & 27.2 & 28 & 2 & 27.8 & 27.7 & 27.3 & 1.7 \\
MCHC & 31.7 & 31.5 & 31.8 & 1.6 & 31.8 & 31.6 & 31.6 & 1.3 \\
RDW & 15 & 14 & 13 & 1 & 14 & 14 & 14 & 1 \\
\hline
\end{tabular}

Hb: Haemoglobin, RBC: Red cell count, MCV: Mean corpuscular volume, MCH: Mean corpuscular haemoglobin, MCHC: Mean corpuscular haemoglobin concentrate, RDW: Red cell distribution width.

Table 2 Morphology data from blood film analysis 


\begin{tabular}{|c|c|c|c|c|c|c|}
\hline Morphology & Status & LID & LID & Normal & Normal & $\begin{array}{l}\text { Significance } \\
\text { (Pearson Chi } \\
\text { Square Test) }\end{array}$ \\
\hline \multirow{2}{*}{$\begin{array}{l}\text { Normal red } \\
\text { cells }\end{array}$} & 0 & 1 & $0.50 \%$ & 1 & $0.60 \%$ & - \\
\hline & 1 & 191 & $99.50 \%$ & 162 & $99.40 \%$ & 0.907 \\
\hline \multirow{2}{*}{$\begin{array}{l}\text { Hypochromic } \\
\text { microcytic } \\
\text { red cells }\end{array}$} & 0 & 101 & $52.60 \%$ & 117 & $71.80 \%$ & - \\
\hline & 1 & 91 & $47.40 \%$ & 46 & $28.20 \%$ & 0.00 \\
\hline \multirow[t]{2}{*}{ Acanthocytes } & 0 & 169 & $88.00 \%$ & 148 & $90.80 \%$ & - \\
\hline & 1 & 23 & $12.00 \%$ & 15 & $9.20 \%$ & 0.399 \\
\hline \multirow[t]{2}{*}{ Pencil cells } & 0 & 82 & $42.70 \%$ & 93 & $57.10 \%$ & - \\
\hline & 1 & 110 & $57.30 \%$ & 70 & $42.90 \%$ & 0.007 \\
\hline
\end{tabular}

Note: 0- Absent, 1- Present on the blood film 